\title{
An experimental approach to reconstruction of wool dyeing in archaeology
}

\author{
Franka Ovčarić \\ Branka Tomić
}

https://doi.org/10.17234/METARH.2019.7

\author{
Franka Ovčarić \\ Centre for Scientific Research and \\ Popularization of Archaeology, ZipArh \\ Ilica 126 \\ HR - 10000 Zagreb \\ franka.ovcaric@gmail.com \\ Branka Tomić \\ Ivekovićeva 17 \\ HR - 10000 Zagreb \\ tomic.branka9@gmail.com
}

Textile in archaeology has long been seen as an unreliable source of data due to the lack of methods that deal with the processing of such findings. Only during the last couple of years, serious analyses have begun to take place. It was often possible to reconstruct the look of fabrics and decorative objects, while searching for color traces in fibers has rarely been done. Since the first traces of dyed textiles were found, the process itself had already been developed, yet the experimental stage of selection and development of the dyeing process stays unknown. In that case, answers to a variety of questions can be offered by experimental archaeology and interdisciplinary approach. As a starting point, some experiments that have already been done involving fabric dyeing will be used and mentioned later in work (Cardon 2007; Vajanto 2011; Grömer 2016). It took several steps, such as collecting and processing wool, selecting natural dye sources, dyeing the wool and analyzing the obtained samples. In collaboration with other branches of natural and human sciences, information about the past becomes more complete, and the interpretation itself more accurate.

Keywords: natural dye, mordant, experimental archaeology, walnut, elderberry

\section{Introduction}

As an archaeological find, the textile is considered to be highly valuable because specific preservation conditions are required, which are almost never suitable for both plant and animal fibers (Sutlović 2008; Grömer 2016: 23). Research is mostly focused on the finished product itself or fabric production technology after the fiber is already made, most notably weaving. The process of dyeing fabrics and substances needed for it were seldom stressed although over the last decade there have been some significant papers considering the subject (Cardon 2007; Andersson Strand 2010; Vajanto 2011; Grömer 2016). Though most pigments and mordants are 
defined by ethnoarchaeological and historical sources, the whole palette of colors and mordants used on archaeological textile remains unknown. The most interesting aspect of the process which has not yet been fully discovered is the selection and development of the pigments and mordants. Each mordant is suitable for a particular type of fiber, and the choice and combination of mordant and pigment significantly affect the longevity and durability of the dye (Schoeser 2009: 30; Vajanto 2011; Grömer 2016: 23). In this experiment, green walnut husks were used as a pigment source, since they are known as the source of pigments in the prehistoric times (Grömer 2016: 23). Second pigment source used were black elderberries, whose pigment is sensitive to sun exposure (Bechtold and Mussak 2009). The goal was to confirm the importance of plant selection and the use of mordants. The mordants used in the experiment were mainly produced by using metal residues and slag. The dyeing experiment was mostly based on oral ethnological sources and modern literature, which is another indication of a strong tradition which is universal throughout the whole Europe (Cardon 2007; Schoeser 2009; Dean 2010; Grömer 2016).

\section{Textile in archaeology}

Textile in archaeology has long been seen as an unreliable source of data due to the lack of methods that deal with the processing of such findings. Textile is a particularly sensitive archaeological find since it is rarely recovered because of its difficult preservation (Bender Jørgensen and Walton 1986; Grömer 2016). Conditions required for the preservation of textiles at a site include: stable $\mathrm{pH}$, constant temperature, anaerobic or aerobic environment, and the presence or absence of certain bacteria and fungi (Grömer 2016: 25). Because fabrics of plant and animal origin require different preservation conditions, they are rarely preserved in the same context. The degree of preservation may vary from partial to complete and depends on the combination of preservation conditions (Grömer 2016: 25). Since the first traces of dyed textiles date from the period when the process itself had already been developed, the experimental stage of selection and development of the coloring process is still unknown (Grömer 2016: 25). Therefore, answers to a variety of questions can be offered by experimental archaeology guided by archaeological finds and ethnoarchaeology (Bender Jørgensen and Walton 1986; Schoeser 2009).

\section{Methodology}

The experiment consisted of several steps, such as collecting and processing the wool, selecting the natural dyes based on ethnological and archaeological sources, dyeing the wool and analyzing the samples (Sutlović 2008; Schoeser 2009; Andersson Strand 2010; Vajanto 2011; Grömer 2016). The aim of experiment was to reconstruct the production process of collecting and treating the raw material and finally dyeing the wool for comparison with the archaeological material and the context in which it can be found (Bender Jørgensen and Walton 1986). Pigments were extracted from the selected plants and mixed with metal or salt and vinegar-based mordants (Dean 2010; Vajanto 2011). Color durability was tested on each sample to better understand the selective phases of the development of pigments and/or mordants. Macroscopic and microscopic analyses were performed on the obtained samples, color-code parameters were determined, and a map of colors was made for the samples dyed with a variety of mordants and dyes. The experiment was done in three phases: preparation, experimentation and analysis and processing of the collected results. During the preparation, the first step was to collect and prepare wool by sorting, washing in pure natural water, and drying. In the experimental phase, the prepared wool was treated with the mixtures which contained naturally obtained dyes and mordants. The first group of samples was treated using metal-based mordants, while the other group was treated with a mixture of salt and vinegar. The third control unit was dyed without presence of mordants for better understanding the importance and reasons for the development and use of mordants (Manlin and Xiaoming 2013: 596; Schoeser 2009: 30). Mordant is a substance that acts as fiber color fixator which in combination with pigments results in better colorfastness and it is used for obtaining different hues in the production of colors. All of the used wool was dipped in plain water before soaking in mordants. Because they required certain preparation time (Bechtold and Mussak 2009), the three used mordants were prepared a few months before the experiment. Two of the mordants used were metal-based and the main components were iron and copper, the recipe that was based on the ethnoarchaeological studies (Manlin and Xiaoming 2013: 594; Grömer 2016). These mordants were obtained by immersing metal waste (old nails or scrap metal) into a mixture of water and vinegar (Dean 2010: 42; Grömer 2016: 154). The third type of mordant was made by adding $5 \mathrm{ml}$ of vinegar and salt mixture per 100 $\mathrm{ml}$ of water. To monitor the effect of acidity or alkalinity on the hue and saturation of the color obtained, each 
pots $\mathrm{pH}$ value was measured. Black elderberries and green walnut husks were used as sources of pigments (Bechtold and Mussak 2009: 156). Because of the presence of tannins which may serve as a color fixator, walnut husks were selected as they are a well known natural dye source (Grömer 2016). Because the elderberry dye is sensitive to the external influences (Dean 2010: 130131), it was possible to record the importance of variables such as choice of mordants and length of dyeing while using elderberries as the source of pigment. The collected data resulted in a better understanding of the selective phase of choice of mordants and plants suitable for pigment extraction. continued for the 140 minutes with samples taken every 30 minutes. The last samples were taken after cooling. The dyed samples were subsequently rinsed in water and dried (Table 1).

\section{Results}

All of the dyed samples were subjected to macroscopic and microscopic analyses (Vanden Berghe 2013: 58). The first and simplest was organoleptic analysis. Samples were examined and the subjective rating of hue/ color was made. The biggest change in hue and color

\begin{tabular}{|c|c|c|c|c|}
\hline \multicolumn{5}{|c|}{ BLACK ELDERBERRIES } \\
\hline Mordant & $\begin{array}{l}\text { Without } \\
\text { mordant }\end{array}$ & Vinegar+salt & Copper mordant & Iron mordant \\
\hline \multicolumn{5}{|l|}{ Samples } \\
\hline Color & $\begin{array}{c}\text { Dark } \\
\text { purple-red }\end{array}$ & Intense pink-red & $\begin{array}{l}\text { Dark coppery } \\
\text { red-purple }\end{array}$ & $\begin{array}{c}\text { Dark blue, almost } \\
\text { black }\end{array}$ \\
\hline Fineness & Coarse & Coarse & Coarser & The Coarsest \\
\hline \multicolumn{5}{|c|}{ WALNUT HUSKS } \\
\hline Mordant & $\begin{array}{l}\text { Without } \\
\text { mordant }\end{array}$ & Vinegar+salt & Copper mordant & Iron mordant \\
\hline \multicolumn{5}{|l|}{ Samples } \\
\hline Color & Brown & Bright brown & Dark brown & $\begin{array}{l}\text { Red- brown with } \\
\text { purple undertone }\end{array}$ \\
\hline Fineness & Coarse & Coarse & Coarser & The Coarsest \\
\hline
\end{tabular}

TABLE 1.Table of obtained colors and hues considering the use of pigment and mordant (Made by Ovčarić F. and Tomić B.)
Firstly, parts of the selected plants were crushed to form a paste and dipped in water for 24 hours. The next day, the mixture was boiled for 60 minutes and sifted through the cloth after cooling. The resulting color bath was additionally diluted. Next, the wool was soaked in plain water for 60 minutes and then additionally in mordants for another 60 minutes (Vajanto 2014: 65). For each color bath, $10 \mathrm{~g}$ of wool and $1000 \mathrm{ml}$ of dye were weighed and measured. They were placed in the pot and gradually heated to the boiling point after which the dyeing saturation was noticed on samples treated with metal base mordants and on the same samples, change in fineness of fibers occurred. Samples treated with metalbased mordants appeared coarser to touch than samples without mordant and with salt and vinegar as mordant. The colors on the samples were subjectively evaluated. Subsequently, an analysis was performed using a digital loupe with 90X magnification. On fibers soaked in metal base mordants, areas of larger color accumulation and stains of unknown origin were visible and further 


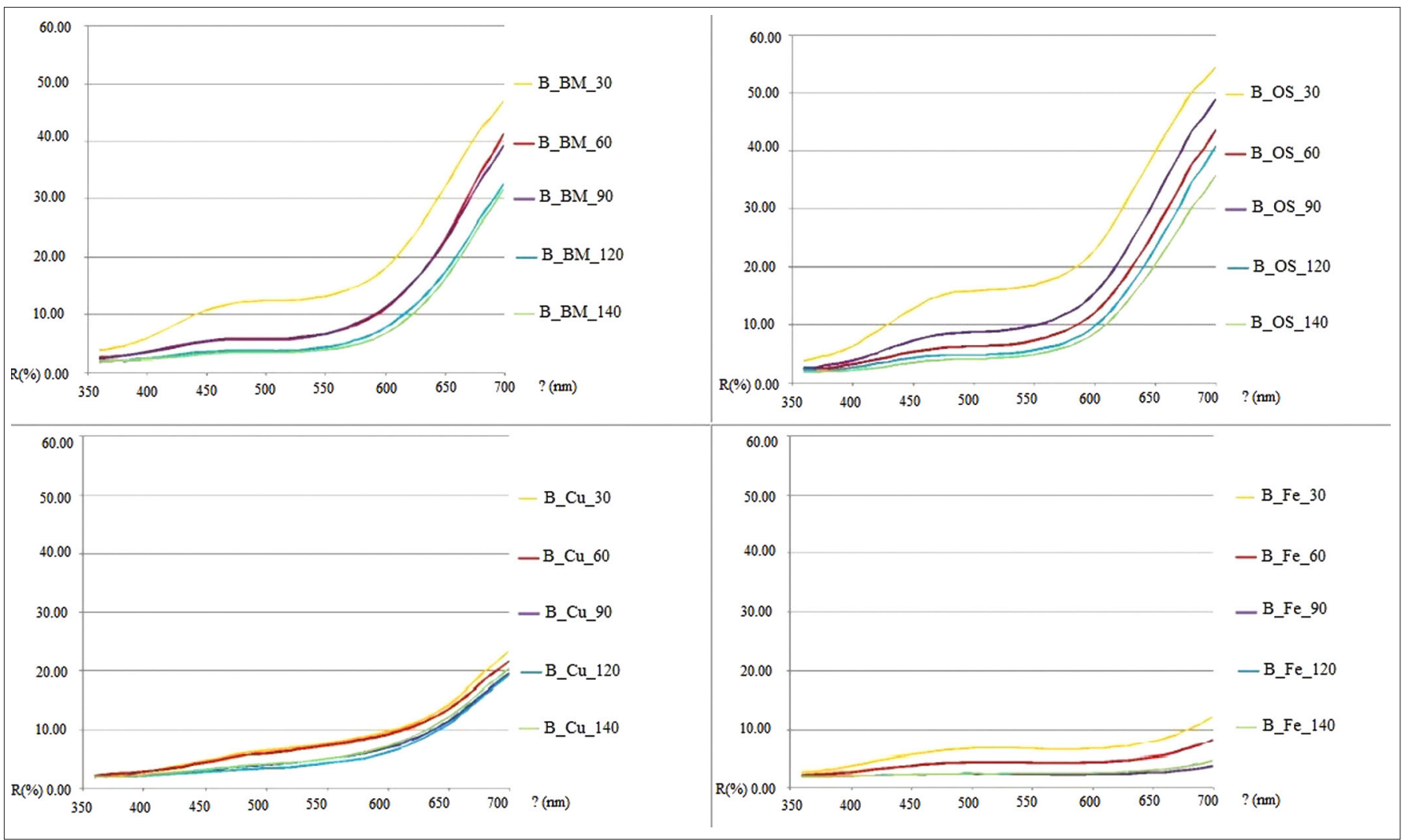

FIGURE 1. Remission curve when dyed with black elderberries (B-elder, BM-without mordant, OS-vinegar+salt, Cu-Copper, Fr-Iron, Number-Duration of dyeing) (Made by Ovčarić F. and Tomić B.)

analysis with electron microscope and energy dispersive spectroscopy analyses were performed. For the electron microscope analysis, a sample of raw wool was taken, as well as samples dyed with elderberries and walnut husks soaked in metal-based mordants. After that, the samples were subjected to analysis through energy dispersive spectroscopy and it confirmed the inorganic nature of the material after treatment with metal salts. Copper presence of $1.58 \mathrm{wt} . \%$ and iron presence of $0.22 \mathrm{wt} . \%$ was shown in regards to other visible elements that are part of the wool fiber itself. Spectrophotometric analysis showed that the samples dyed with elderberries, both with and without mordant, belong to the orange-red part of the color spectrum. Samples soaked in metalbased mordants had higher hue values and appeared to belong to the orange-yellow part of the color spectrum. A change of hue was not observed, and samples became black, in particular the iron mordanted samples. Samples soaked in vinegar and salt were red-hued, which could be seen organoleptically as these samples had the brightest hue of color. On the remissive spectrophotometer, the coloristic parameters such as brightness, hue and chromaticity/saturation and the value of remission in the visible part of the spectrum were determined. On these graphs, we can see the remission curves which show that:

- On the samples dyed with elderberries and walnut husks but without mordants it can be seen that color depth is the largest on the sample that was thermally treated the longest (140 minutes).

- On the elderberry sample with the addition of salt and vinegar, highest color saturation is achieved at the 140th minute and on the walnut husk sample at the 120th minute.

- All the samples dyed with the addition of copper gained the highest coloration at the 120th minute.

- Iron-treated samples have the highest color saturation in comparison to all others, maximum remission is seen after 90 minutes on the elder sample and after $120 \mathrm{~min}$ utes on the walnut sample.

To determine the stability of wool coloration, samples were exposed to sunlight and washed in order to determine if the fabric could have been worn in everyday life. (Vajanto 2014: 62-70). Previously prepared lye was obtained by boiling wood ash in water to achieve a slightly 
alkaline $\mathrm{pH}$. Using laboratory appliances adjusted to certain parameters, washing was simulated. To analyze the influence of sunlight, samples were put on the window sill for a month and exposed to sunlight. Afterwards, everything was subjected to spectrophotometric analysis. The obtained results confirm that the color remains more stable on washed samples than on samples exposed to sunlight. After exposure to sunlight, the coloring fades but the hue does not change and the samples dyed with both plant dyes have very poor stability without the addition of metals(Vajanto 2014: 62-70).

\section{Discussion}

In the samples dyed with elderberries, it was observed that the coloration shows the highest value in the sample which has been thermally treated the longest (140 minutes). Samples dyed with elderberries and bathed in a solution of vinegar and salt also showed the highest coloring depth value after 140 minutes. Wool dyed with elderberries and a copper-based mordant solution resulted in a deeper color tone than wool dyed without mordant and with the addition of vinegar and salt, which, according to previous sources, could have been expected (Bechtold and Mussak 2009). In this case, the highest color depth value was achieved after 120 minutes, while the sample dyed for 140 minutes has a lower coloring depth value than the sample dyed for 90 minutes. Samples dyed with elderberries and dyed in the iron-based mordant exhibited an even greater coloring depth value than those in the copper-based mordant solution since the iron-based mordant was the strongest and the most aggressive mordant used in the experiment (Bechtold and Mussak 2009). The remission maximum for this case was achieved after the 90th minute of dyeing and further thermal treatment of the sample lowered the color depth value (Fig.1).

Samples dyed with walnut husks without the addition of mordants showed the same results as the samples dyed with elderberries. In both cases, the color depth value was increased by prolonging the dyeing process. For samples dyed in vinegar and salt-based mordant, the highest coloring depth value was recorded in the 120th minute of the dyeing process and the coloring depth value decreased with the prolonged dyeing. Samples dyed in a copper-based mordant solution showed the

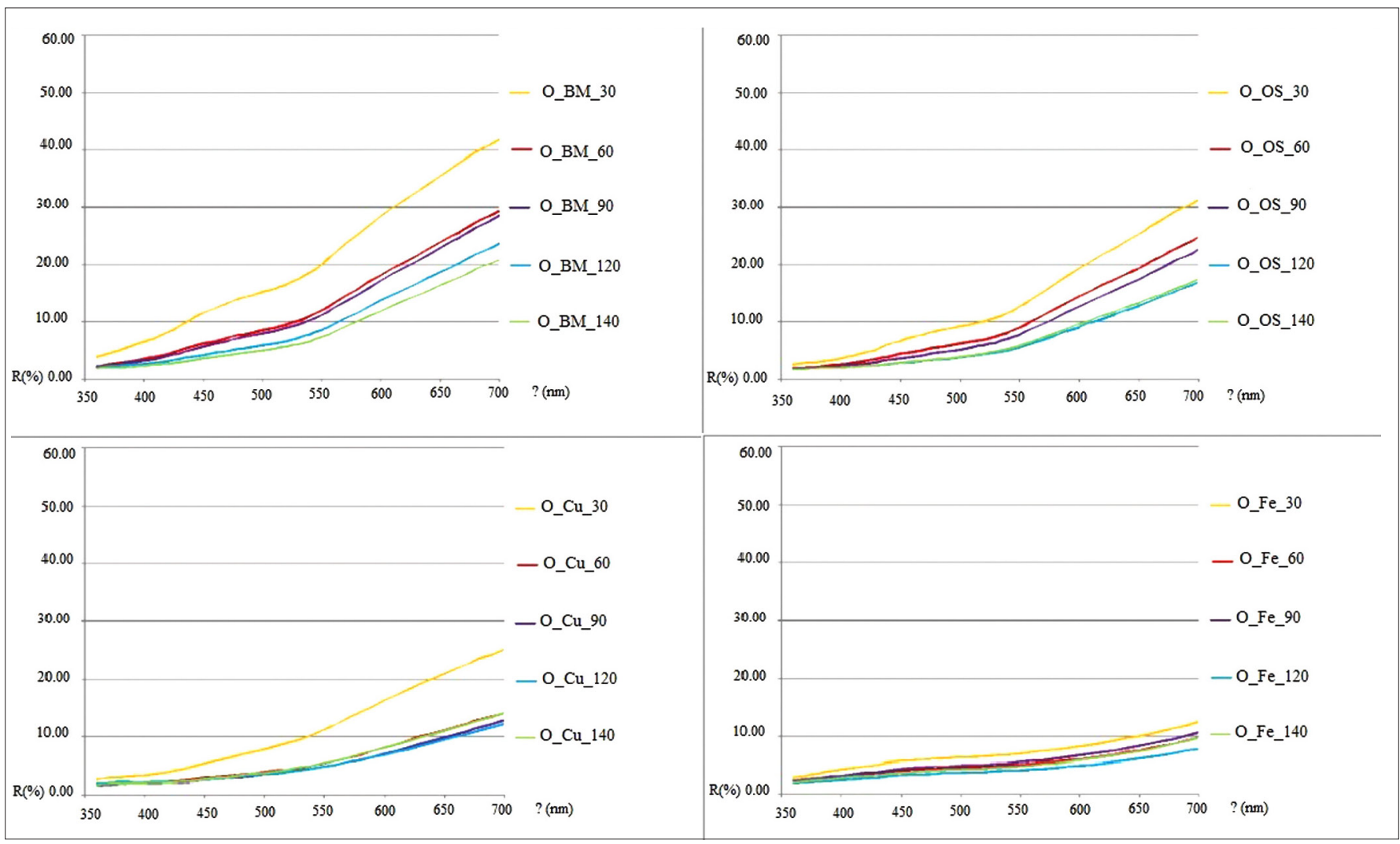

FIGURE 2. Remission curve when dyed with green walnut husks (O-walnut, BM-without mordant, OS-vinegar+salt, Cu-Copper, Fr-Iron, NumberDuration of dyeing) (Made by Ovčarić F. and Tomić B.) 
highest coloring depth value after 120 minutes of dyeing and further dyeing decreased this value. In this case, the coloring depth value of the sample dyed for 140 minutes was similar to the color of the sample dyed for $60 \mathrm{~min}-$ utes. For samples dyed in a strong iron-based mordant solution, the greatest coloring depth value was achieved after 120 minutes of dyeing and the sample that had been dyed the longest exhibited a lesser color depth value, similar to the sample dyed for 60 minutes (Fig. 2).

According to the results obtained, it can be concluded that when dyeing fibers without mordants and with the vinegar and salt-based mordants, greater duration of the dyeing process results in a greater coloring depth value. Also, the samples dyed in elderberry water extract have a pronounced peak between 470 and $500 \mathrm{~nm}$, consistent with the obtained red tones of wool. Wool samples dyed with green walnut husks extract were dark brown, and the remission curves had no pronounced peak. Patterns dyed with elderberries, with and without mordants, belonged to the orange-red part of the color spectrum. Differences were observed between samples dyed with the metal-based mordant, and samples dyed without mordants and in the vinegar and salt-based mordant solution. Samples dyed with a metal-based mordant showed a higher hue which approaches towards the orangeyellow area of the color spectrum. However, due to the lower value of the chromaticity and the brightness, the change in the tones could not be observed, or rather, it was perceived as "black" in particular samples dyed in iron-based mordants. Samples dyed with vinegar and salt mordant solution showed a value of $h *<45$ which confirmed their red tone as it was seen organoleptically. These samples have the "brightest" color tones. The sample dyed for 90 minutes was perceived as darker. Samples dyed with walnut husks also belonged to the orange part of the color spectrum, with slightly yellower hue than samples dyed with elderberries. It was noted that samples dyed without mordants and samples dyed with vinegar and salt mordant solution exhibited similar chromaticity. Samples dyed in a copper-based mordant were more chromatic, whereas the samples dyed in an iron-based mordant were most saturated. When the samples dyed with plant-based dyes were compared, it is seen that a similar reaction occurred. Various sources (Dean 2010; Grömer 2016) mention that tannins in combination with iron give dark, almost black tones. In this experiment, samples dyed with elderberries and the iron-based mordant resulted in a noticeably darker coloration than samples dyed with walnut husks in the same iron-based mordant. Samples dyed with elderberries in an iron-based mordant resulted in a very dark, al- most black color, which was expected, but not achieved in samples dyed with walnut husks (Grömer 2016).

\section{Conclusion}

Some plants are more and some less suitable for dyeing, so there was a selection phase of suitable dyes. Due to the coloring and mordant conditions, a wide range of hues were obtained. The choice of mordant significantly affects the hue and colorfastness. Green walnut husks produce a more stable color due to the presence of tannins. It has been confirmed that using metal salts as mordants can achieve significant coloration with shorter dyeing time. Instrumental methods in fiber analysis and metal presence can be made successful and determine the degree of damage and also indicate the traces of metals in fiber that can affect human health as well as the dyeing process. The development of the use of metals and the availability of metal ore may have been the key moments not only in metallurgy but also in textile production. Since archaeological research into prehistoric color remains is still developing, this experiment is intended to be repeated with other dyes with the goal of better future understanding and comparing the results within the archaeological context.

\section{Acknowledgements}

We are particularly grateful for the assistance given by dr. sc. Janja Mavrović Mokos and dr. sc. Ana Sutlović during our research. We wish to acknowledge the help provided by mag. ing. techn. text. Iva Matijević with carrying out the analyzes.

We want to express our deep gratitude to dear colleagues and friends Štefanija Kožić, Valentina Lončarić, Matko Vlahović and Dalibor Branković for numerous readings of our manuscript and offering advice during our research. 


\section{References}

Andersson Strand, E. 2010. Experimental Textile Archaeology, In: E. Andersson Strand, M. Gleba, U. Mannering, C. Munkholt and M. Ringgaard (eds.), North European Symposium for Archaeological Textiles $X$, Ancient Textiles Series vol. 5, Oxbow Books, Oxford, 1-3.

Bechtold, T. and Mussak, R. 2009. Handbook of natural colorants, Wiley and Sons Inc, New Jersey.

Bender Jørgensen, L. and Walton, P. 1986. Dyes and Fleece types in Prehistoric Textiles from Scandinavia and Germany, Journal of Danish Archaeology 5, 177-188.

Cardon, D. 2007. Natural Dyes. Sources, Tradition, Technology and Science, Archetype Publications, London.

Dean J. 2010. Wild color, Watson-Guptill Publications, New York.

Grömer, K. 2016. The Art of Prehistoric Textile Making The development of craft traditions and clothing in Central Europe, Veröentlichungen der Prähistorischen Abteilung (VPA) 5, Natural History Museum Vienna.
Manlin, W. and Xiaoming, Y. 2013. Experimental Study of Natural Organic Dyes from Ancient Europe, Trans Tech Publications, Switzerland, Vol. 821-822, 593-596.

Schoeser, M. 2009. Svijet tekstila: kratka povijest, Golden marketing/Tehnička knjiga, Zagreb.

Sutlović, A. 2008. Studij prirodnih bojila-doprinos humanoj ekologiji, unpublished PhD Thessis, University of Zagreb, Faculty of Textile Technology.

Vajanto, K. 2011. Natural mordants, Journal for Weavers, Spinners \& Dyers 238, 287-331.

Vajanto, K. 2014. Textile standards in experimental archaeology, In: Focus on Archaeological Textiles: Multidisciplinary Approaches. Monographs of the Archaeological Society of Finland, MASF 3, 62-75.

Vanden Berghe, I. 2013. Dye analysis of Archaeological Textile Objects, The North European Symposium for Archaeological Textiles XI, 2011 Esslingen am Neckar, Verlag Marie Leidorf GmbH-Rahden/Westf. Publication. 